\title{
Stress perception among patients in pre-colonoscopy period and those undergoing chemotherapy treatment
}

\author{
Percepção de estresse entre pacientes em período pré-colonoscópico e em tratamento \\ quimioterápico
Percepción de estrés entre pacientes en período precolonoscópico y en tratamiento quimioterápico

Graziela de Souza Alves da Silva ${ }^{1}$, Gabriela Alves Vieira da Silva ${ }^{1}$, Camila Cristine Antonietti ${ }^{1}$, Sonia Betzabeth Ticona Benavente ${ }^{1}$, Rodrigo Marques da Silva ${ }^{1}$, Ana Lucia Siqueira Costa ${ }^{1}$

Objective: comparing the perception of stress among patients with colorectal cancer undergoing chemotherapy with those in pre-colonoscopy period. Methods: a comparative descriptive study developed with 144 people receiving chemotherapy and 100 patients in the pre-colonoscopy period, using biosocial and clinical data, Stress Assessment Tool and Perceived Stress Scale. Results: a predominance of females (73\%), aged over 65 (50\%) were predominant for the pre-colonoscopy period patients. In patients receiving chemotherapy, gender parity with ages ranging from 40-64 years (68.1\%) was observed. Precolonoscopy patients showed higher perceived stress compared to those receiving chemotherapy $(p<0.001)$. Conclusion: the phase of diagnostic definition represents greater stress to patients in comparison to period of treatment, even despite the characteristic manifestations of chemotherapy.

Descriptors: Colorectal Neoplasms; Stress, Psychological; Colonoscopy; Drug Therapy.

Objetivo: comparar a percepção de estresse entre pacientes com câncer colorretal em tratamento quimioterápico com aqueles no período pré-colonoscópico. Métodos: estudo descritivo, comparativo, desenvolvido com 144 pessoas em quimioterapia e com 100 pacientes em período pré-colonoscópico, utilizando-se formulário de dados biossociais e clínicos, o Instrumento de Avaliação de Estresse e a Escala de Estresse Percebido. Resultados: dos pacientes em período pré-colonoscópico, houve predominância do sexo feminino (73\%), na faixa etária acima de 65 anos (50\%). Daqueles em quimioterapia houve paridade quanto aos sexos e a maioria se encontrava na faixa etária de 40 a 64 anos (68,1\%). As pessoas no período pré-colonoscópico apresentaram maior estresse percebido quando comparado àqueles em quimioterapia $(\mathrm{p}<0,001)$. Conclusão: a fase de definição diagnóstica representa maior estresse aos pacientes em comparação ao período terapêutico, mesmo diante das manifestações características da quimioterapia.

Descritores: Neoplasias Colorretais; Estresse Psicológico; Colonoscopia; Quimioterapia.

Objetivo: comparar la percepción de estrés entre pacientes con cáncer colorrectal sometidos a quimioterapia con aquellos en el período precolonoscópico. Métodos: estudio descriptivo, comparativo, desarrollado con 144 personas en quimioterapia y 100 pacientes en el período precolonoscópico, mediante formulario de datos biosociales y clínicos, la Herramienta de Evaluación de Estrés y la Escala de Estrés Percibido. Resultados: en los pacientes en el período precolonoscópico, hubo predominio del sexo femenino (73\%), mayores de 65 años (50\%). Los de la quimioterapia no había paridad que los sexos y la mayoría estaban en el rango de edad de 40 a 64 años $(68,1 \%)$. Las personas en el período precolonoscópico mostraron mayor estrés percibido en comparación con aquellos que reciben quimioterapia $(\mathrm{p}<0,001)$. Conclusión: la fase de definición de diagnóstico representa mayor estrés a los pacientes en comparación con el período de tratamiento, incluso antes de las manifestaciones características de la quimioterapia.

Descriptores: Neoplasias Colorrectales; Estrés Psicológico; Colonoscopía; Quimioterapia.

\footnotetext{
${ }^{1}$ Escola de Enfermagem, Universidade de São Paulo. São Paulo, SP, Brazil. 


\section{Introduction}

Colorectal cancer is a type of curable and treatable cancer when diagnosed in its early stages ${ }^{(1-2)}$. The World Health Organization advises the implementation of public preventive measures to combat different types of cancer, either by health promotion with early diagnosis by screening for diseases, or in the treatment of primary and/or secondary tumors ${ }^{(3)}$. Regarding screening tests, fecal occult blood test (blood in the stool), sigmoidoscopy and colonoscopy are recommended ${ }^{(2)}$. The possible or confirmed diagnosis of any type of malignant neoplasm causes emotional impacts on individuals, because they represent a progressive and painful journey ${ }^{(4)}$.

The diagnosis of colorectal cancer stands out in particular because colonoscopy is an uncomfortable examination for the patient; it can trigger feelings of vulnerability, shame, fear and pain even prior to the procedure ${ }^{(5)}$, as well as apprehension and fears about the results thereof. With regards to therapy, the main treatment options found today are surgery, chemotherapy and radiotherapy. When analyzing the multimodality of treatment, we highlight chemotherapy because of the associated side effects, which may include alopecia, cardiac and gastrointestinal alterations, nausea, weak immune system, social isolation and changes in their daily life routine, among other impacts on a patient's quality of $\operatorname{life}^{(3-4)}$.

Therefore, the period involving colorectal cancer diagnosis as characterized by the colonoscopy, as well as chemotherapy, and given its organic and psychological consequences, can be perceived as stressful by individuals and can cause stress. In this context, according to the Interactionist Model of Stress, stress occurs when a situation is evaluated as taxing or exceeding adaptive resources of an individual or social system. This involves the socalled cognitive evaluation, in which the individual classifies the situation in a number of evaluative categories, defining them as challenges or threats. In this design, the possibility of disease and the experience of chemotherapy effects may be assessed by the individuals in different ways, and as such they may or may not be perceived as stressors ${ }^{(6)}$. In a study with colorectal cancer patients which compared the intensity of stress presented by patients going through three distinct situations (surgery, surgery and chemotherapy, or surgery and radiotherapy), it was observed that patients undergoing chemotherapy after surgery had higher stress intensity when compared to other groups, showing that the produced side effects from the treatment of colorectal cancer is perceived as stressful to the patient ${ }^{(7)}$.

However, an extensive search performed in the literature reveals a lack of studies that report this comparison. Therefore, there is a need to understand the impacts of colonoscopy procedures and chemotherapy treatment, and consider their peculiarities in stress perception. The results may provide subsidies to guide nursing team's actions in comprehensive patient care, increasing knowledge in this area.

From the foregoing, this study aimed to compare the perception of stress among colorectal cancer patients undergoing chemotherapy to those in the pre-colonoscopic period.

\section{Method}

This is an exploratory study of an analytical and quantitative approach. Data collection occurred in two different institutions. Subjects undergoing chemotherapy were approached in the Cancer Institute of São Paulo, while patients in precolonoscopy period were approached at the University Hospital of the University of São Paulo. This research involves patients from two different institutions, as the results come from the comparison of two databases produced by researchers at the University of São Paulo at different periods of time. Since both institutions have been partners since $2011^{(8)}$, and 
therefore have similar protocols for cancer patient care, it was possible to compare the stress between both groups (in diagnostic and therapeutic phases), even at different times.

The sample dimension of chemotherapy in patients was based on a simple random sampling on the number of patients/month undergoing chemotherapy for colorectal cancer in the outpatient Oncology Clinic of the São Paulo State Cancer Institute. The confidence interval was $95 \%$ and statistical power $80 \%$. The sample consisted of 144 patients. Data were collected between June 2012 and January 2013, through interviews at the time with individuals receiving chemotherapy after they had signed the Informed Consent form.

As for the patients in the pre-colonoscopy period, the sample size calculation was based on multiple linear regression of ten predictors for patients in pre-colonoscopy procedure with a 95\% confidence interval and 90\% statistical power. Thus, we determined a sample of 100 patients. Data were collected from April to July 2011 in the Endoscopy Unit of the University Hospital of the University of São Paulo, through interviews on the day of the exam, after that the final preparation for the colonoscopy was concluded.

During interviews, both groups of patients were given biosocial and clinical data forms, as well as a Perceived Stress Scale consisting of 10 items. The biosocial and clinical data form was designed for the group in pre-colonoscopy procedure, and the information was related to: gender, age, marital status, education, number of examinations carried out, indication of colonoscopy procedure and prior knowledge. For the group of cancer patients undergoing chemotherapy, the form evaluated the following information: gender, age, marital status, education, diagnosis time and chemotherapy treatment.

The Perceived Stress Scale has been validated for adults in Brazil ${ }^{(9)}$. It is designed so that individuals can evaluate stressful experiences in the last past month, according to their own perception. The scale has 10 items arranged in a five point Likert scale, wherein: 0-never; 1-almost never; 2-sometimes; 3-almost always; and 4-always ${ }^{(9)}$.

Data were organized, stored and analyzed using the Statistical Package for Social Sciences (version 20.0). The qualitative variables were presented by absolute frequency (n) and percentage (\%), and quantitative variables through descriptive measures (minimum, maximum, average and standard deviation). To view the data of the Perceived Stress Scale, we used the median values and quartiles along with a boxplot chart. For comparison analysis between the means of both groups to the scale used, we employed the Student t-test. P values of $\mathrm{p}<0.001$ were considered statistically significant.

In order to assess the internal consistency of the instruments, the Cronbach's alpha test was performed for the total score and separately for the 10 items in the two populations. Alpha values greater than 0.5 were considered satisfactory to attest to significant instrument reliability with Cronbach alpha coefficient greater than $0.5^{(10)}$.

For chemotherapy patients, the project was approved by the Research Ethics Committee of the University of São Paulo School of Nursing (Protocol no.1005/2011) and by the Ethics Committee of the Faculty of Medicine, University of São Paulo (Protocol no.154/2011). For the study of individuals in precolonoscopy period, the research was approved by the Ethics Committee of the Nursing School at the University of São Paulo (Protocol no. 1011/2011) and the Research Board of the Education and Research Commission, University Hospital, University of São Paulo.

\section{Results}

Of the 100 patients in the pre-colonoscopy period, we observe a predominance of women $(73.0 \%)$, over 65 years of age $(50.0 \%)$, followed by those at 40-64 years (41.0\%), in some kind of affective relationship (90.0\%) and with a secondary education 
level (33.0\%). In the 144 patients undergoing chemotherapy, there was gender parity with the majority in the age range of 40-64 years (68.1\%), in some kind of affective relationship (91.6\%), and a primary education level (67.8\%).

Table 1 shows the distribution of patients in precolonoscopy period according to the characteristics related to the colonoscopy procedure.

Table 1 - Distribution of patients in pre-colonoscopy period $(n=100)$ according to inherit characteristics of the colonoscopy procedure

\begin{tabular}{ll}
\hline $\begin{array}{l}\text { Inherent characteristics of the colonoscopy } \\
\text { procedure }\end{array}$ & $\mathbf{n ( \% )}$ \\
\hline Previous examinations & $15(15.0)$ \\
None & $19(19.0)$ \\
1 & $66(66.0)$ \\
$\geq 2$ & \\
Reason for colonoscopy* & $29(29.0)$ \\
Bleeding/anemia/change in bowel habits/ & $21(21.0)$ \\
abdominal pain & $68(68.0)$ \\
Inflammatory bowel disease & $20(20.0)$ \\
Family history of colon cancer & $15(15.0)$ \\
Control after colon tumor resection & \\
Tracing/search for cancer and polypoid lesions & \\
Prior knowledge of the procedure & $23(23.0)$ \\
A diagnostic test for colon diseases & \\
As a means of colon disease diagnosis and & $77(77.0)$ \\
as previous preparation for the procedure & \\
\hline Total exceeds sampling due to the possibility of choosing 2 or more reasons
\end{tabular}

Patients experienced in the examination procedures were predominant, having performed it two or more times $(66.0 \%)$, along with family history of colon cancer $(68.0 \%)$. Yet, patients believe that colonoscopy aims to diagnose colon diseases, with a need of specific preparation for the procedure (77.0\%).

Table 2 shows the distribution of patients undergoing chemotherapy for colorectal cancer according to their clinical characteristics.
Table 2 - Distribution of patients undergoing chemotherapy for colorectal cancer according to their clinical characteristics

\begin{tabular}{lc}
\hline $\begin{array}{l}\text { Clinical characteristics of patients with colorectal } \\
\text { cancer undergoing chemotherapy }\end{array}$ & $\mathbf{n}(\%)$ \\
\hline Diagnosis time (months) & \\
$0-6$ & $63(47.3)$ \\
$7-12$ & $40(30.1)$ \\
$13-24$ & $9(6.8)$ \\
$25-60$ & $19(14.3)$ \\
$61-300$ & $2(1.5)$ \\
Losses & $11(7.6)$ \\
Chemotherapy Treatment & \\
Adjuvant & $91(65.0)$ \\
Neoadjuvant & $4(2.9)$ \\
Palliative & $45(32.1)$ \\
Losses & $4(2.8)$ \\
\hline
\end{tabular}

A prevalence of patients at the beginning of treatment and under one year of diagnosis for the tumor $(77.4 \%)$ can be observed, while adjuvant chemotherapeutic treatment to surgery is the most common (65.0\%). (Table 2).

Regarding reliability of the Perceived Stress Scale for the populations studied, we identified the Cronbach's alpha as 0.583 and 0.77 for patients in precolonoscopic procedure and chemotherapy treatment, respectively. These numbers attest to satisfactory instrument reliability ${ }^{(10)}$.

Individuals in the pre-colonoscopy period obtained higher scores of perceived stress (median $=25$, with between 18 and 26 points), than patients undergoing chemotherapy (median $=15$, with values between 9 and 19 points). (Figure 1 and Table 3).

Comparing minimum and maximum values, mean, standard deviation and quartiles among patients, the perceived stress score among the groups show statistically significant difference ( $\mathrm{p}<0.001)$. Individuals in pre-colonoscopy period have higher perceived stress in relation to the group of patients undergoing chemotherapy (Table 3). 
Table 3 - Comparison of the Perceived Stress Scale among patients in pre-colonoscopy procedure and those undergoing chemotherapy treatment

\begin{tabular}{lccccccc}
\hline \multirow{2}{*}{ Patients } & \multicolumn{5}{c}{ Perceived Stress Scale } \\
\cline { 2 - 7 } & Minimum & Maximum & Average* & SD $^{* *}$ & Median & 1st quartile & 3rd quartile \\
\hline Pre-colonoscopy & 9 & 27 & $22.3^{*}$ & 5.3 & 25 & 18 & 26 \\
Chemotherapy treatment & 0 & 34 & $14.4^{*}$ & 6.8 & 15 & 9 & 19 \\
${ }^{*}$ Student $t$-Test $(\mathrm{p}<0.001)^{* *}$ Standard Deviation & & &
\end{tabular}

\section{Discussion}

In recent years, the State has strengthened planning for prevention, control and care for patients with cancer. Although the disease combat strategies are important, those of preventive character are essential since different cancers are curable if treated in their early stages ${ }^{(2,11)}$. For this reason, the diagnosis must be carried out promptly, which can be done though a colonoscopy ${ }^{(11)}$.

In this context, of the 100 patients in the precolonoscopy period, we observed a predominance of women $(73.0 \%)$, over 65 years of age $(50.0 \%)$, followed by those at 40-64 years (41.0\%), in some kind of emotional relationship (90\%) and secondary education levels (33.0\%). The predominance of women within the recommended age range for lowrisk patient screening ( $>50$ years) may be related to the fact that they seek health services more often than men, regardless of education levels. Thus, they can be diagnosed with different types of cancer at earlier stages, specifically colorectal cancer, and therefore mortality rates in this group are lower. This is confirmed by data collected in a systematic review carried out in several international databases ${ }^{(1,12)}$. In this review, it was found that women seek health services and adhere to preventive measures of cancer, such as the colonoscopy, more often than men. Incidence and mortality rates were different between genders, so that women die less than men due to colorectal cancer ${ }^{(1,12)}$.

Regarding clinical aspects, there was a predominance of experienced patients who had had the procedure performed twice or more times before $(66.0 \%)$ and had a family history of colon cancer (68.0\%). Preventive colonoscopy should be performed in low-risk individuals every 5 years after 50 years of age and every 10 years in people over 60 years. However, in risky populations of more than 50 years of age with a personal or family history of cancer or polyps, a colonoscopy should be performed at the early age of $40^{(1)}$. In this context, it is important to note that family history is a determinant risk factor for cancer, as researchers have identified a significant relationship between first degree family history and increased risk of tumors in studies of pancreatic tumors $^{(13)}$. Therefore, the identification of persons at increased risk of cancer related to family history through accurate and detailed patient records is essential, specifying types of tumors, age, diagnosis, location and confirmation of information ${ }^{(13)}$. Thus, it becomes possible to forward them to intensive screening, genetic counseling and establish early interventions for disease prevention or control ${ }^{(13)}$.

In addition to the above, this research shows that patients believe that a colonoscopy aims to diagnose colon diseases, with the need for specific preparation for the procedure (77.0\%). Regarding the procedure, this finding may be understood as positive, since the knowledge of the issues involved in health care and in procedures minimizes the emotional stress and anxiety of the patient and reduces postprocedure complications ${ }^{(14)}$. In this sense, it highlights the importance of efficient health education, which 
depends on the use of language easily understood and different teaching methods by health professionals, especially nurses, who are mainly responsible for giving guidelines prior to medical and surgical procedures $^{(13)}$.

Among the 144 patients undergoing chemotherapy, the population was equally divided between gender, with a predominance of those aged from 40-64 years (68.1\%), in some kind of emotional relationship (91.6\%) and with primary education level (67.8\%). In a study of 58 outpatients treated at an Iranian oncology hospital receiving chemotherapy for various cancers, it was identified that $30 \%$ were men and $70 \%$ women, with an average age of 53.4 years $^{(15)}$. In a research conducted with 60 individuals from Pozega (Croatia) diagnosed with gastrointestinal cancer (56 with colon or rectum cancer, two in the stomach and two in the pancreas), they found a predominance of men $(73.3 \%)$ with an average age of 68.70 years $( \pm 9.2)$, and a predominance of married patients $(91.7 \%)$ with secondary education levels $(48.3 \%)^{(16)}$. In another study of 70 patients with colorectal cancer in Saudi Arabia, they observed patients with an average age of 53.6 years $( \pm 12.2$ ) where $48.6 \%$ were men and $51.4 \%$ were women, $77.1 \%$ were married, $70 \%$ living with a partner and children, and 50\% with secondary education level ${ }^{(17)}$. Based on these findings, it is clear that the profile exhibited by Brazilian patients undergoing chemotherapy is similar to the profile observed in international research, that is, individuals who are married or are in a stable relationship, with ages of indicative being adults and elderly. However, the occurrence of cancer varies according to the gender of the studies presented, which can be related to the type of cancer involved in each research. Still, the patients' level of education in international studies is higher (Secondary Education) to those verified in this investigation (Primary education). On top of that, the relationships between low educational levels and difficulty of access to information, and therefore studies have pointed out that there is greater difficulty in recognizing the symptoms of the disease. Accordingly, men take longer to search for healthcare and therefore they are diagnosed with increased detection risk for advanced tumors, when therapies tend to be more aggressive and worse prognoses are expected $^{(5,14)}$.

In terms of colorectal cancer diagnosis and treatment, we observed a predominance of patients at the beginning of treatment and under one year of diagnosis of the tumor (77.4\%), and adjuvant chemotherapeutic treatment to surgery is the most used (65\%). In a study conducted in Saudi Arabia, it was observed that the patients were diagnosed approximately 2 years earlier, the most frequent intervention was surgery $(95.7 \%)$, and that chemotherapy therapy was the most common adjuvant treatment (78.6\%), followed by radiotherapy (18.6\%) (17). It was observed that patients were in treatment for a considerable time after diagnosis, having already gone through the diagnostic confirmation stage, and all the difficulties experienced at the beginning of treatment due to doubts and side effects related to chemotherapy, as well as fears related to surgery. Regarding the same issue, in a systematic review with breast cancer patients as the target population, it was found that they also go through different difficult times in the diagnostic phase, including the suspicion of tumor presence and the confirmation of medical diagnosis $^{(18)}$. These moments are considered stressful for patients because they relate to death. However, in this period, coping changes also occur, bringing forth positive expectations aimed at healing, hoping to return to "normal," changes that facilitate the treatment and minimize stress $^{(18)}$. This context may partly explain the results found when comparing perceived stress among patients undergoing chemotherapy and those in the diagnostic phase, as stress perceived by individuals in the pre-colonoscopy procedure phase is higher when compared to the stress of patients undergoing chemotherapy for colorectal cancer. In a study conducted with 100 patients undergoing chemotherapy for colorectal cancer at the AC Camargo 
Hospital, Sao Paulo, a low level of perceived stress was observed with 12.05 points on the Perceived Stress Scale ${ }^{(19)}$, which strengthens the findings of this research.

In addition, it is worth mentioning that the colorectal cancer screening is carried out mainly through colonoscopy and that despite being an accurate method of diagnosis, it can only be done with adequate bowel preparation. To obtain a high quality examination, that being one that enables clear visualization of the large intestine mucosa for proper medical diagnosis, it requires large volumes of laxatives, which makes the process uncomfortable, painful and stressful ${ }^{(11)}$. Concerning this, a study of 100 patients in the pre-colonoscopy period revealed that the care involved in the preparation of the colon, such as sedation, and the body's exposure in relation to the access point for the exam and their discomfort made individuals feel stressful, and were common factors for refusing the exam. Yet, in a case-controlled research ${ }^{(11)}$ performed in 200 subjects (100 cases and 100 controls), they found that people with inflammatory bowel disease reported the presence of pain and nausea during intestinal wash in ileocolonoscopy procedures as stressful situations. In addition, the author states that the younger the patients are, the more ashamed and insecure they feel due to the anatomical location and characteristic of the exam, and the elderly feel worried about the results ${ }^{(11)}$.

In addition to previous tests, surgeries and countless invasive procedures, patients with colorectal cancer also face chemotherapy. Similar to this research, in a study of 400 German patients recently diagnosed with colorectal cancer, they observed a predominance of patients with moderate level of stress at the beginning of the treatment. After six months of treatment, it was observed that the number of individuals with high stress decreased from $27 \%$ to $18 \%$, with statistically significant differences ${ }^{(20)}$. In this sense, it is believed that chemotherapy represents less stress for these patients due to the advantages that are weighted in the "cost-benefit" analysis against the side effects, whether being physical or psychological ${ }^{(19-21)}$. Therefore, possibly because it is a new event, it causes a degree of stress at first, but when patients understand that this is an option for controlling or curing the disease, chemotherapy is perceived as a method/tool to combat disease and/or fight for their life ${ }^{(19-21)}$.

Based on these results, it is important to understand that the colorectal cancer discovery process is perceived as more exhausting for patients than for those undergoing treatment itself. This is strengthened by the assertion that chemotherapy has provided remarkable optimism in the treatment of cancer and has been increasing the survival rate of patients, although the time between diagnosis and acceptance of the disease varies according to each individual ${ }^{(22)}$. In addition to the above, it is important to highlight that progress in the pharmaceutical field has also provided more effective control of the side effects from chemotherapy, for example nausea and vomiting through the association of different drugs, which makes this a less demanding process nowadays ${ }^{(23)}$. So it is important that effective coping strategies are developed and used by the patients, and social support provided by family and health professionals is effective in minimizing stress, especially during the diagnosis period.

\section{Conclusion}

In comparing perceived stress among patients in pre-term colonoscopy and those undergoing chemotherapy, it was found that the perception of stress is higher in the former compared to the latter. It is believed that the fears related to diagnosis and the characteristic discomforts of colonoscopy justify the greater perception of stress in these patients. Moreover, the understanding of chemotherapy as a way of coping with the disease, the significance of this treatment as a way to continue living, and the availability of more effective drugs to control the side effects of chemotherapy may explain the lower 
perception of stress among patients in treatment.

This research presented a scenario that allows for reflection on the different stages of the healthdisease process, a dynamic case present in the life of every individual in their different situations, as well as self-knowledge, assessment and reassessment of essential stressors for safely and effectively coping with the disease.

However, in this study it is emphasized that there was a comparison of different groups of patients, with cross-cutting and at different moments of time being limitations of this research. Such analyzes does not allow for establishing causal relationships between the intensity of stress and diagnosis or treatment, but knowing for which group the intensity of this phenomenon was higher.

Therefore, it is suggested to conduct future studies in which the same patients are analyzed and followed from the time of diagnosis and treatment until their survival with colorectal cancer over a longer period of time.

\section{Collaborations}

Costa ALS and Antonietti CC contributed to construction of the project, and conducting the study. Benavente SBT, Silva GSA, Silva GAV and Silva RM all contributed to the study design, analysis and interpretation of data, article writing and approved the final version to be published.

\section{References}

1. Fang CB. Rastreamento para câncer colorretal. Rev Assoc Med Bras. 2002; 48(4):286.

2. Than M, Witherspoon J, Shami J, Patil P, Saklanic A. Diagnostic miss rate for colorectal cancer: an audit. Ann Gastroenterol. 2015; 28(1):94-8.

3. World Health Organization (WHO). The World Health organization's fight against cancer: strategies that prevent, cure and care. United States of America: World Health Organization; 2014.
4. Miles A, Atkin WS, Kralj-Hans I, Wardle J. The psychological impact of being offered surveillance colonoscopy following attendance at colorectal screening using flexible sigmoidoscopy. J Med Screen. 2009; 16(3):124-30.

5. Dázio EMR, Sonobe HM, Zago MMF. The meaning of being a man with intestinal stoma due to colorectal cancer: an anthropological approach to masculinities Rev Latino-am Enfermagem. 2009; 17(5):664-9.

6. Lazarus RS, Folkman S. Stress appraisal and coping. New York: Springer; 1984.

7. Pereira MG, Figueiredo AP, Fincham FD. Anxiety, depression, traumatic stress and quality of life in colorectal cancer after different treatments: a study with Portuguese patients and their partners. Eur J Oncol Nurs. 2012; 16(3):227-32.

8. Fundação Faculdade de Medicina (FMM). ICESP, uma referência no tratamento de câncer. J FMM. [periódico na Internet] 2012 [citado 2015 Jan 13]; 64:1-12. Disponível em: http://extranet. ffm.br/wfcontent/subportals/Imprensa/Jornal/ Jornal64.pdf

9. Reis RS, Hino AA, Añez CR. Perceived stress scale: reliability and validity study in Brazil. J Health Psychol. 2010;15(1):107-14.

10. Bailar J, Mosteller F. Medical users of statistics. Boston: Nejm Books; 1992.

11. Bessissow T, Van Keerberghen CA, Van Oudenhove L, Ferrante M, Vermeire S, Rutgeerts $P$, et al. Anxiety is associated with impaired tolerance of colonoscopy preparation in inflammatory bowel disease and controls. J Crohns Colitis. 2013; 7(11):580-7.

12. Krishnan S, Wolf JL. Colorectal cancer screening and prevention in women. Womens Health (Lond Engl). 2011; 7(2):213-26.

13. Haugvik SP, Hedenström P, Korsæth E, Valente R, Hayes A, Siuka D, et al. Diabetes, smoking, alcohol and family history of cancer as risk factors for pancreatic neuroendocrine tumors: a systematic review and meta-analysis. Neuroendocrinology. [Internet] 2015 [cited 2015 Apr 13]; 101(2): Available from http://www.karger.com/Article/ Abstract/375164 
14. Silva RM, Soares RSA, Lana LD, Birrer JA, Mostardeiro SCTS. Percepção de pacientes com neoplasias esofágicas e estomacais sobre orientações pré-operatórias recebidas do enfermeiro. Rev Enferm UFSM. 2011; 1(3):431-9.

15. Mansourabadi A, Moogooei M, Nozari S. Evaluation of Distress and Stress in Cancer Patients in AMIR Oncology Hospital in Shiraz. Iran J Ped Hematol Oncol. 2014; 4(4):131-40.

16. Galic S, Glavic Z, Cesarik M. Stress and quality of life in patients with gastrointestinal cancer. Acta Clin Croat. 2014; 53(3):279-90.

17. Al Ahwal MS, Al Zaben F, Khalifa DA, Sehlo MG, Ahmad RG, Koenig HG. Depression in patients with colorectal cancer in Saudi Arabia. Psychooncology. [Internet] 2014 [cited 2015 Jan 13]. Available from: http://onlinelibrary.wiley.com/ doi/10.1002/pon.3706/epdf

18. Silva MB da, Miranda FAN de, Pessoa Júnior JM. Feelings and expectations of women diagnosed with breast cancer: a reflection. J Nurs UFPE on line. [Internet] 2013 [cited 2015 Jan 13]; 7(spe):4965-71. Available from: http://www. revista.ufpe.br/revistaenfermagem/index.php/ revista/article/view/3383/pdf_3063
19. Benavente SBT, Monteiro EMS, Costa ALS. Diferencias de género en la percepción de estrés y estrategias de afrontamiento en pacientes con cáncer colorrectal que reciben quimioterapia. Aquichan. 2015; 15(1):9-20.

20. Landsbergen KM, Prins JB, Brunner HG, Van Duijvendijk P, Nagengast FM, Van Krieken JH, et al. Psychological distress in newly diagnosed colorectal cancer patients following microsatellite instability testing for Lynch syndrome on the pathologist's initiative. Fam Cancer. 2012; 11(2):259-67.

21. Caetano EA, Gradim CVC, Santos LES. Câncer de mama: Reações e enfrentamento ao receber o diagnóstico. Rev Enferm UERJ. 2009; 17(2):25761.

22. Nicolussi AC, Sawada NO, Cardozo FMC, Andrade V, Paula JM. Quality of life in hematologic oncology patients undergoing chemotherapy. Rev Rene. 2014; 15(1):132-40.

23. Castro MC, Araújo AS, Mendes TR, Vilarinho GS, Mendonça MA. Effectiveness of antiemetics in control of antineoplastic chemotherapyinduced emesis at home. Acta Paul Enferm. 2014; 27(5):412-8. 